\title{
ADJUSTING OF THE WEIGHTING SCHEME USING PENALTY METHODS IN THE BUSINESS AND CONSUMER SURVEYS
}

\author{
[Úprava váhového schématu výpočtu konjunkturálních průzkumů]
}

\author{
Veronika Ptáčková ${ }^{1}, J$ iř́ Novák ${ }^{2}$, Lubomír Štěpánek $^{3}$ \\ ${ }^{1}$ Prague University of Economics and Business, Faculty of Informatics and Statistics \\ W. Churchill Sq. 1938/4, 13067 Prague 3 \\ Email:veronika.ptackova@vse.cz. \\ ${ }^{2}$ Prague University of Economics and Business, Faculty of Informatics and Statistics \\ W. Churchill Sq. 1938/4, 13067 Prague 3 \\ Email:xnovj159@vse.cz. \\ ${ }^{3}$ Prague University of Economics and Business, Faculty of Informatics and Statistics \\ W. Churchill Sq. 1938/4, 13067 Prague 3 \\ Email: lubomir.stepanek@vse.cz
}

\begin{abstract}
The Business and Consumer Survey is a commonly used and easy-to-follow tool for describing the current and near-future situation in the national economy. A lot of countries use leading indicators for economic predictions. The computations of the indicators are generally based on weighting schemes considering the importance of each survey questions groups. The European Commission harmonizes the weighting schemes for those calculations.

In this article, we adjust the weighting scheme of the Economic Sentiment Indicator as the main result of the Business and Consumer Survey and design a new weighting structure of the calculation. To find a new weighting scheme, we use a combination of a penalty method which measures L3-based-norm distance between all original weights and the proposed ones, adapting the weight system to the Czech economic data. Applying the penalty functions is a method of respecting the original, empirically estimated weights used for the indicator's calculations on a long-term basis. The modified weighting scheme for the Economic Sentiment Indicator construction is supposed to ensure better predictions and, eventually, provide early warnings about any unexpected changes in the business cycle in the national economy.
\end{abstract}

Keywords: business and consumer survey, optimization, prediction ability, weighting scheme.

JEL classification: $\mathrm{C} 10, \mathrm{C} 22$

Received: 2.10.2020; Reviewed: 28.10.2020; 4.12.2020; Accepted: 16.12.2020

\section{Introduction}

Living in such uncertain times, we want to find statistical indicators that would give us information about future economic development. In current world, we know that we use the data which are important for the politician decisions and strategies for the next development. Unfortunately, quantitative data (as Gross Domestic Product, Gross Value Added or the Industrial production index) are published with the delay. It is a reason why we are looking for the leading indicators. Among the tons of them, we prefer the most informative ones and call them leading indicators. A leading indicator is an economic statistical indicator that changes before general economic conditions and therefore can be used to predict turning points in the business cycle. Typical examples of leading indicators are stock prices, business and consumer expectations. A leading indicator is distinct from both a coincident indicator, changing simultaneously with economic conditions, and lagging indicator, reflecting changes in the general economic trend only after they have already taken place (Eurostat 2020). 
We can mention some of the most favourite and used leading indicators: the Ifo Business Climate Index, the ZEW Indicator of Economic Sentiment (both are popular in Germany), the OECD Composite Leading Indicator (CLI) or the Economic Sentiment Indicator (taken patronage over by the European Commission). This article focuses on the latter. The Economic Sentiment Indicator is the main output of the Business and Consumer Survey. The European Commission harmonized the calculation of the Economic Sentiment Indicator - the main output of the Business and Consumer Surveys. One of the weaknesses of the calculation has been mentioned many times in literature reviews - the weighting scheme. In the Czech Republic, the Czech Statistical Office is responsible for the Business and Consumer Survey. The Czech Statistical Office collects data from respondents in the business sectors, while an external company manages collecting information about the consumers. Then the Czech Statistical Office calculates the final indicator (from the collected responses). Firstly, confidence indicators in the five surveyed sectors are calculated. These indicators describe overall perceptions and expectations in each sector (industry, construction, trade, selected services, consumers). After that, Economic Sentiment Indicator is calculated as the signal of overall economic activity. This indicator is calculated since 1985. Economic Sentiment Indicator is correlated with a referent series as year-on-year growth in industrial production at European Union or euro-area level (European Commission 2020). From 2020, European Commission publishes Employment Expectations Indicator which describes changes in the employment. In this paper, we will focus only on Economic Sentiment Indicator.

Leading indicators, especially Business and Consumer Surveys, are beneficial for the predictions and information about the describing the mood and confidence in the economy (see chapter Literature review). Aforementioned data sources can fill in the gap about the current situation, economic significance, cyclical behaviour or lead at turning points. Unfortunately, there are problems during the calculation which get worse the precision of the survey. Because we want the quick, accurate data, we have to get better calculation. One of the ways for an improvement is a change in the weighting scheme.

This paper aims - according to the previous paragraph - to find a new weighting scheme, maximizing the precision of the indicator predictions and minimizing the distances between the original and new weights, respectively. To ensure the latter demand, we modify the utility function firstly introduced in (Ptáčková et al. 2019) by penalizing the weights very dissimilar to the original scheme, on behalf of getting more realistic weight estimates.

\section{Literature review}

According to the European Commission's methodology, Business and Consumer Surveys provide primary information that can be used for economic monitoring, short-term forecasting, and the economic cycle, respectively. The first surveys were taken in the manufacturing sector in 1962. The construction sector was added in 1966, the consumer sector in 1972, the retail trade sector in 1984, and the selected services sector in 1996 (European Commission 2020). Surveys provide important information mainly in countries that are based on market relations. From the answers from the respondents, we know what the mood is in the economy and what are the tendencies for future development (Czech Statistical Office 2020).

Business and Consumer Survey are one of the composite indicators (which were mentioned in the Introduction section). According to the Organisation for Economic Co-operation and Development and European Commission (2008), mentioned indicators are in the quantitative or a qualitative form from the observed data of, for example, country. Composite indicators 
identify trends and warn before particular issues (Brand et al. 2007). According to Saisana and Tarantola (2002), there are pros and cons of composite indicator (see Table 1).

Table 1: Pros and cons of the composite indicators

\begin{tabular}{|l|l|}
\hline \multicolumn{1}{|c|}{ Pros } & \multicolumn{1}{|c|}{ Cons } \\
\hline $\begin{array}{l}\text { Can summarise complex, multi-dimensional realities } \\
\text { with a view to supporting decision-makers. }\end{array}$ & $\begin{array}{l}\text { May send misleading policy messages if poorly } \\
\text { constructed or misinterpreted. }\end{array}$ \\
\hline $\begin{array}{l}\text { Are easier to interpret than a battery of many separate } \\
\text { indicators. }\end{array}$ & May invite simplistic policy conclusions. \\
\hline Can assess progress of countries over time. & $\begin{array}{l}\text { May be misused, e.g. to support a desired policy, if the } \\
\text { construction process is not transparent and/or lacks } \\
\text { sound statistical or conceptual principles. }\end{array}$ \\
\hline $\begin{array}{l}\text { Reduce the visible size of a set of indicators without } \\
\text { dropping the underlying information base. }\end{array}$ & $\begin{array}{l}\text { The selection of indicators and weights could be the } \\
\text { subject of political dispute. }\end{array}$ \\
\hline $\begin{array}{l}\text { Thus make it possible to include more information } \\
\text { within the existing size limit. }\end{array}$ & $\begin{array}{l}\text { May disguise serious failings in some dimensions and } \\
\text { increase the difficulty of identifying proper remedial } \\
\text { action, if the construction process is not transparent. }\end{array}$ \\
\hline $\begin{array}{l}\text { Place issues of country performance and progress at } \\
\text { the centre of the policy arena. }\end{array}$ & $\begin{array}{l}\text { May lead to inappropriate policies, if dimensions of } \\
\text { performance that are difficult to measure are ignored. }\end{array}$ \\
\hline $\begin{array}{l}\text { Facilitate communication with general public (i.e. } \\
\text { citizens, media, etc.) and promote accountability. }\end{array}$ & $\begin{array}{l}\text { Help to construct/underpin narratives for lay and } \\
\text { literate audiences. }\end{array}$ \\
\hline $\begin{array}{l}\text { Enable users to compare complex dimensions } \\
\text { effectively. }\end{array}$ & $\begin{array}{l}\text { Source: Organisation for Economic Co-operation and Development: Handbook on Constructing Composite } \\
\text { Indicators. Methodology and user guide [online][cit. 20. November 2020]. Accessible from }\end{array}$ \\
https://www.oecd.org/sdd/42495745.pdf >.
\end{tabular}

Business and Consumer Survey are qualitative data - respondents most often choose from a range of three options: that the situation will improve: it will remain the same, it will worsen (especially in the business sector; consumers can used five option scale).

Business leaders answer, for example, the question: How has your production developed over the past 3 months? It has ...

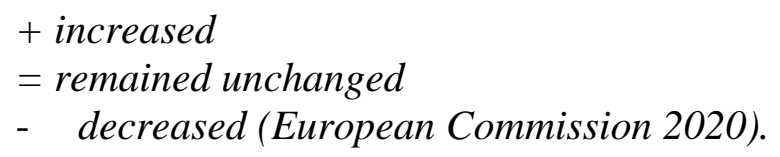

Business and Consumer Survey results are used to monitor areas that are less quantified. A huge advantage of surveys is that the data are always published at the end of the month when the survey is conducted (Czech Statistical Office 2020). In addition to monitoring, they are used for results for economic analysis (see next paragraph).

The outputs of the Business and Consumer Surveys can help with the indicator predictions. People in business fill in the questionnaire about the current and future financial situation or production in the company. Kaufmann and Scheufele (2017) confirm that the questions about the past situation in the company (for example, comparison with the last year) do not have additional information, which we can use for the prediction of the Gross Domestic Product or employment. In Latvia, the business surveys do not help with predictions of the real Gross Domestic Product and real Gross Values Added but they help with the get better precision forecast in the econometric model. In the industry and good sectors, results can make predictions for next five months (Melihovs, Rusakova 2005). 
On the other hand, they mention questions about prices, real activity, and capacity, which are significant for the predictions. Hölzl et al (2019) mention that the Business Survey provides information about an economic upturn or downturn. Focusing on the micro-founded approach, they discovered that the estimates of the micro-founded models are consistent with those of the aggregate models, and the forecasts of the models with sector differentiation are similar to their counterparts of the models without the sector dimension. Lehmann (2020) recommends using the Economic Sentiment Indicator (ESI) for export forecasting. ESI is the best performing indicator for Australia, the Czech Republic, or the Netherlands (for horizon $\mathrm{h}=1$ ), respectively. Ancusa, et al (2015) warn that the results from Business and Consumer Surveys can raise a false expectation in a strictly mathematical interpretation. When we employ a social understanding, these results help with economic development predictions.

Goggin (2008) noted that the potential of the survey data is limited. He suggested that the sample should be significantly larger than has been used so far. There are problems with the companies' heterogeneity - in both the sectors and sub-sectors. The main reason is the current weights (Kearney 1991). Emerson and Hendry (1996) commented that the fixed-weighting scheme, which is applied for predictions throughout the analyzed time, is not performing well. They mentioned it in the list of the weaknesses of the Business and Consumer Surveys - in Latvia; the Business and Consumer Survey does not seem to help much with the short-term forecasting of Gross Domestic Product or Gross Value Added, respectively. However, adopting this information in an econometric model, a more precise forecast can be achieved (Melihovs and Rusakova 2005). In basic way, a lot of statisticians, economists and users are sceptic about the composite indicators - they mention as the reason transparency of some existing indicators (Organisation for Economic Co-operation and Development, 2008), but a lot of analyses confirm the contribution to economic analysis of the economic terms.

\section{Methods and results}

We improve the prediction ability thanks to changing the weighting scheme in the calculation. In the recommendation from the European Commission (2020), we have two approaches:

- simply counting of the answers and

- weighting accounting.

In the Czech Republic, we use the second one. It means that each company has a weighting coefficient (for example the number of sales or employees). The weighting scheme improves the quality of the predictions in the specific sector (European Commission 2020).

\subsection{Current calculation of the Business and Consumer Survey results in the Czech Republic}

Business and Consumer Surveys collect information about the current and future development in the company (sales, production, prices, boundaries, or the level of stocks) and the consumer's opinions (buying durable goods, savings, or worries about the financial situation).

In Figure 1, the development of the composite indicator, business indicator and consumers indicator and the individual indicators - in industry, in construction, in trade and in selected services - from November 2018 to October 2020. There are significant changes during the first wave of the pandemic. The lowest level is during the June 2020 in the industry sector. The construction sector has the smallest impact during the pandemic situation, because there is construction work carried out under contracts. At the end of the curve, we can see the starting of the second wave of pandemic and the decreasing confidence in the economy and worries about the future development in their sectors. 
Figure 1: Business and Consumer Survey development (November 2018 - October 2020)

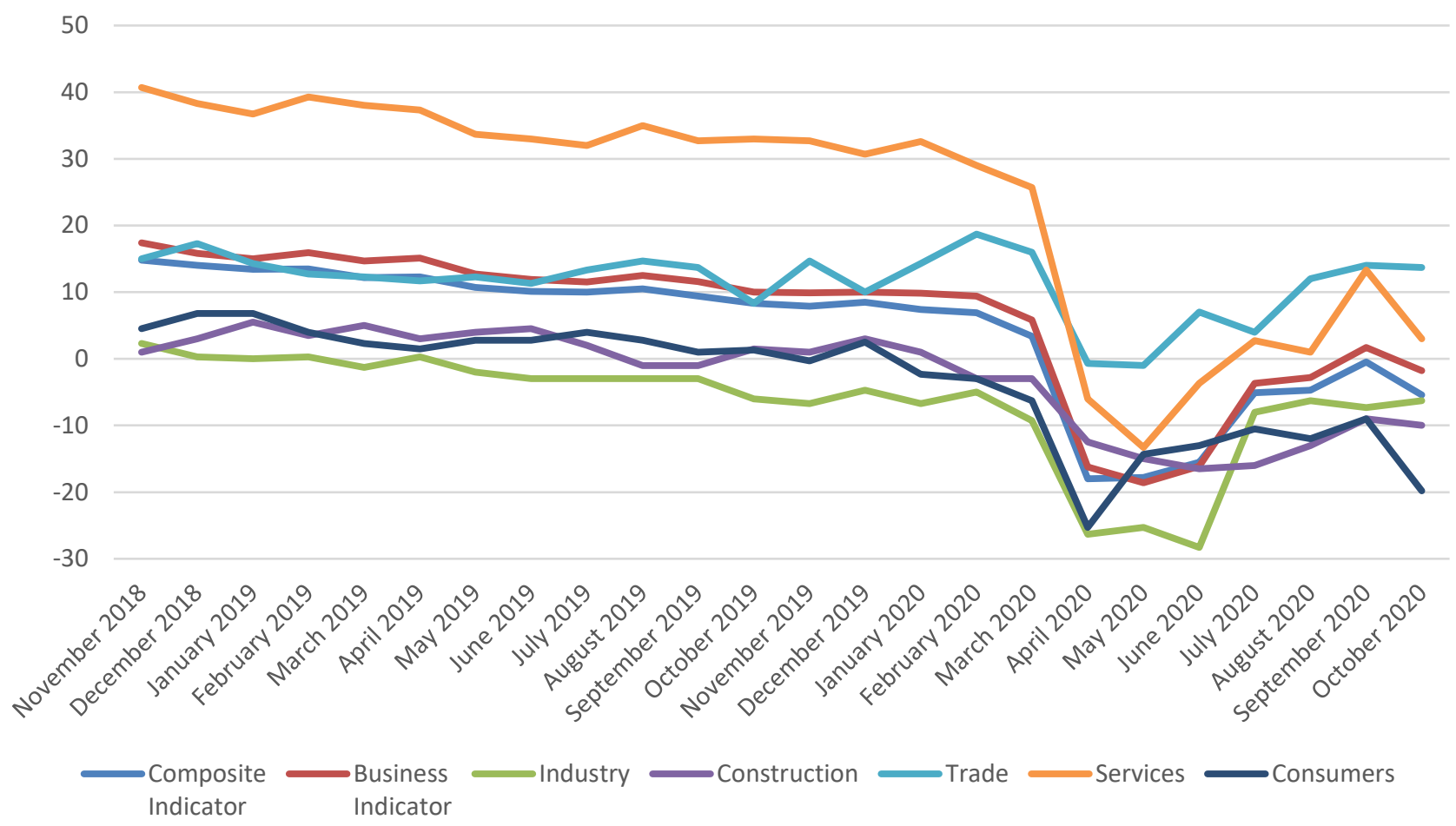

Source: Czech Statistical Office website: Business Cycle Surveys [online][cit. 20. November 2020]. Accessible from < https://www.czso.cz/csu/czso/business_cycle_surveys_ekon>.

After that, employees of the Czech Statistical Office calculate the branch confidence indicators (for industry, construction, trade, and selected services), which is calculated as the difference between the positive and negative responses. It is essential to say that individual confidence indicators have different weight. The current weighting scheme (defined by the European Commission) is described at Fig.2.

Figure 2: Weighting scheme for the Economic Sentiment Indicator (current scheme)

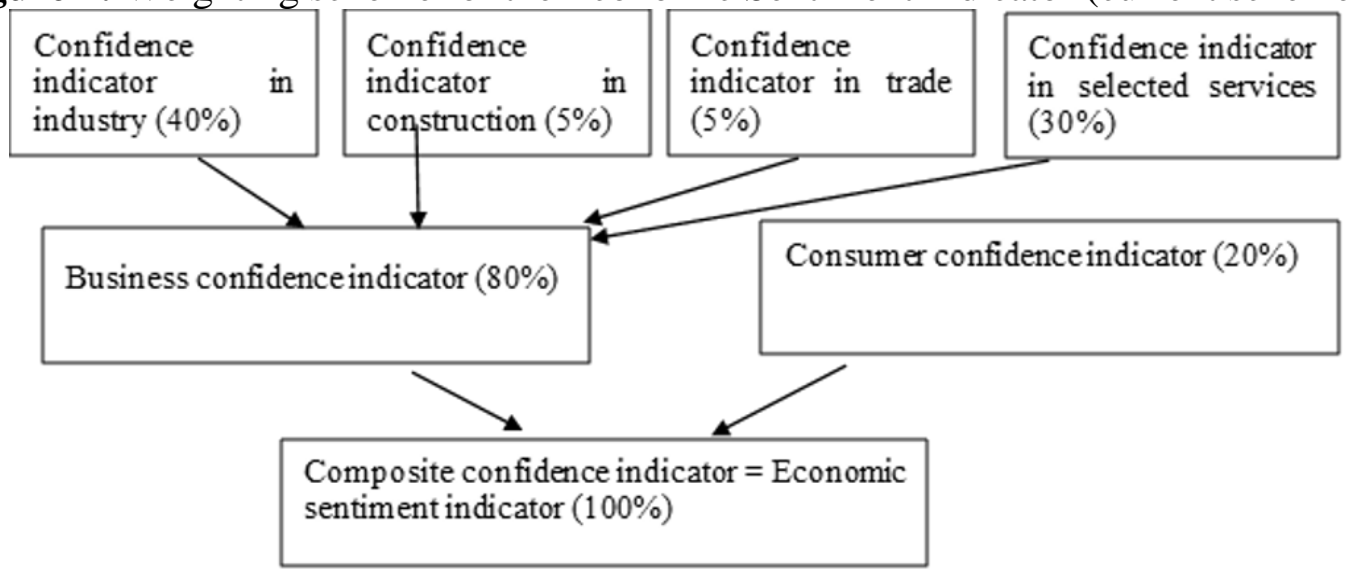

Source: Czech Statistical Offcie website: Business Cycle Surveys [online][cit. 20. November 2020]. Accessible from < https://www.czso.cz/csu/czso/business_cycle_surveys_ekon>.

From these confidence indicators, we calculate the business confidence indicator (80\%). When we add the consumer confidence indicator (20\%), we have the composite confidence indicator, Economic sentiment indicator, respectively (Czech Statistical Office 2020). 
In our paper, we will calculate with the formula of the Economic Sentiment Indicator:

$$
E S I=w_{1} \cdot C I_{1}+w_{2} \cdot C I_{2}+w_{3} \cdot C I_{3}+w_{4} \cdot C I_{4}+w_{5} \cdot C I_{5}
$$

where $C I_{i}$ is $i$-th one of the confidence indicator and $w_{i}$ is $i$-th one of the weights of the confidence indicators such that $i$ is an index of the specific sector from the set \{industrial sector, construction sector, trade sector, selected services sector, consumer sector\}.

The sum of the weights has to be one. The formula should be:

$$
\sum_{i} w_{i}=1
$$

$$
w_{i} \geq 0
$$

where $i$ is an index of the specific sector from the set \{industrial sector, construction sector, trade sector, selected services sector, consumer sector\}.

\subsection{Penalty method}

When weighting the scheme for individual Gross Domestic Product (GDP) indicators, we use optimization with a penalty function, which disadvantages those solutions that are too far from the current empirical weights.

The formula with penalization is following

$$
\begin{aligned}
& \lambda_{1} \max \left\{\operatorname{metric}\left(w_{i}\right)\right\}+\lambda_{2} \max \left\{- \text { penalty error }\left(w_{i}\right)\right\}= \\
& =\max _{i \in\{1,2,3,4,5\}}\left(\lambda_{1} \text { metric }\left(w_{i}\right)-\lambda_{2} \text { penalty } \operatorname{error}\left(w_{i}\right)\right)
\end{aligned}
$$

where $\lambda_{1}$ corresponds to the weight that we assign to the metrics used to select the indicator weights and $\lambda_{2}$ corresponds to the weight that we attribute to the penalization of deviation from the original scales.

The computational approach consists of using a brute force approach, which means that our algorithm goes through all possible combinations of weights, which meet the condition (2) of an amount equal to one and selected are those weights as the best, which maximize the used utility function.

According to our simulations, we can assume that the smaller is the $\lambda_{1}$ (i.e. the greater the emphasis on the penalty from the original values), then the weights of the indicators are the same as the original weights and the larger the $\lambda_{1}$ (i.e. the greater emphasis on the metrics defining new weights of indicators), the more we deviate from the original weights of indicators.

For the examination the penalty method, we will use the following metrics:

- Mean square error = Mean square error is a metric used typically in regression models. The mean squared error of a model with respect to a test set is the mean of the squared prediction errors over all instances in the test set. The prediction error 
can be defined as the difference between the true value and the predicted value (Sammut, Webb 2011).

- Mean absolute error $=$ this metric is also used in the regression models. The mean absolute error of a model with respect to a test set is the mean of the absolute values of the individual prediction errors on over all instances in the test set. Mentioned error can be set as the difference between the true value and the predicted value (Sammut, Webb 2011).

- Correlation coefficient $=$ Correlation coefficient is one of the most used statistical metrics. It is important to mention that correlation measures are nothing but the strength of linear relationship and that it does not necessarily imply a cause-effect relationship. Correlation helps with reduction of the uncertainty (Sharma 2005).

\subsection{Results}

In the search for optimal values of $\lambda_{1}$ and $\lambda_{2}$, we performed the following simulations of how the different values of $\lambda_{1}$ and $\lambda_{2}$ affect the resulting values of indicator's weights.

Figure 3 shows results for used metric of mean square error, and we can see that changes for weights are happening only for $\lambda_{1}<0.2$ and for more significant values, the weights are constant. $\lambda$ equal zero means that we put maximum importance to be as close to the original weights as possible and increasing the values of lambda 1 causes a bigger effect of the used utility function and weights start to vary. For this metric, we can see the highest reduction for the confidence indicator in industry and the biggest gains for the confidence indicator in construction. Another increase can be recorded for confidence indicator in trade, and the remaining indicators show only a small decrease in the calculated weights. According to the metric, the weight composition could look like this: industry $=0.16$, construction $=0.20$, trade $=0.16$, services $=0.28$ and consumers $=0.20$.

Figure 3: Weighting scheme for the Economic Sentiment Indicator (mean square error)

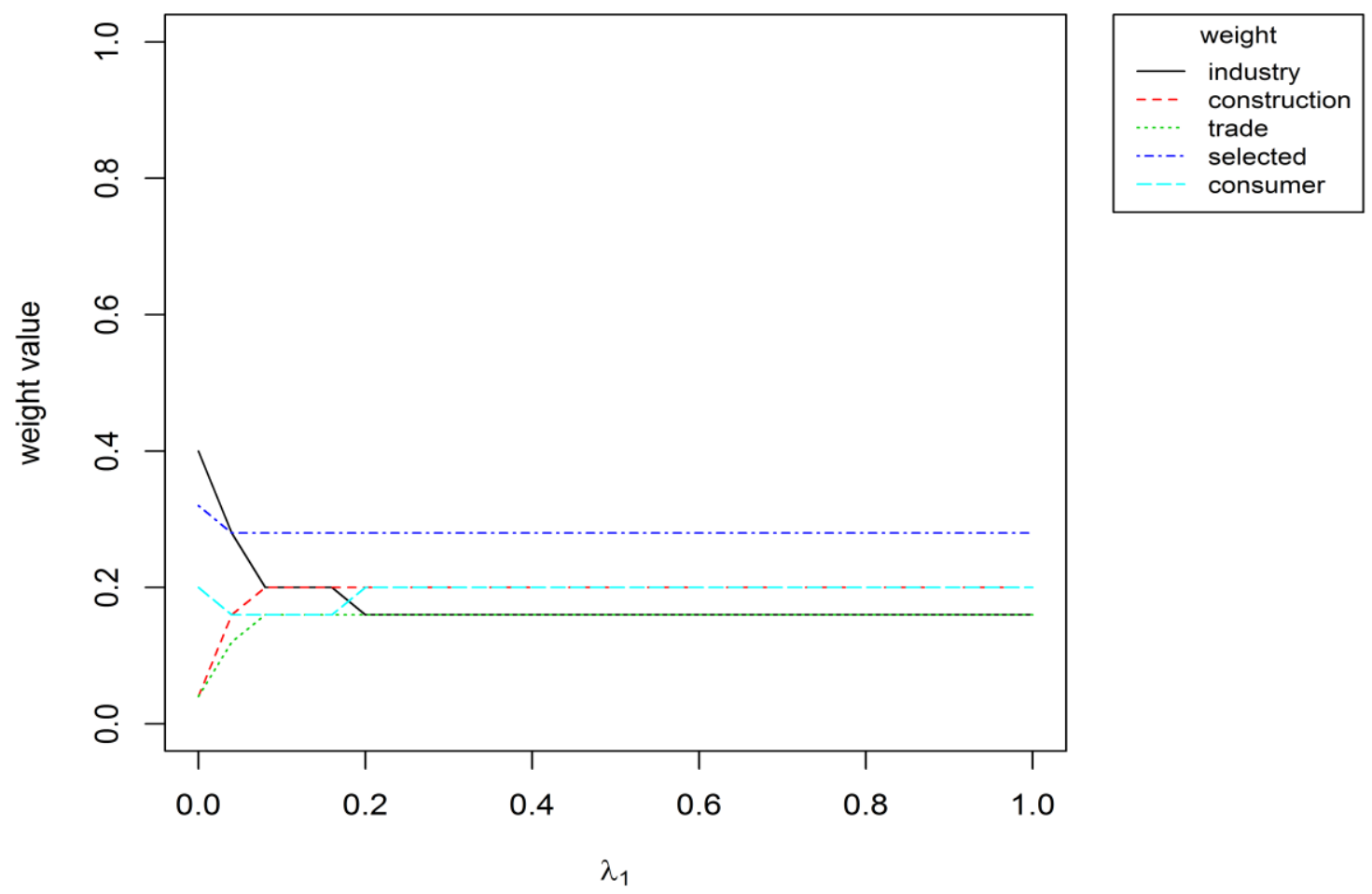

Source: own calculation 
Figure 4 shows results for used metric of mean absolute error and here changes in weights began to occur up after a $\lambda_{1}>0.5$. The confidence indicator in industry is again reduced, and construction gains more significance in weights scheme. Compared to the previous metric, however, the confidence indicator in selected services is growing in importance here. Still, for the rest of the indicators, there is a slight decrease in significance. For the estimation of $\lambda_{1}=(0 ; 0.52)$ and $\lambda_{2}=(1 ; 0.48)$ the weight composition in the structure is suitable: industry $=$ 0.40 , construction $=0.04$, trade $=0.04$, services $=0.32$ and consumers 0.20 . These results are the same as the current weighting scheme from the European Commission.

Figure 4: Weighting scheme for the Economic Sentiment Indicator (mean absolute error)

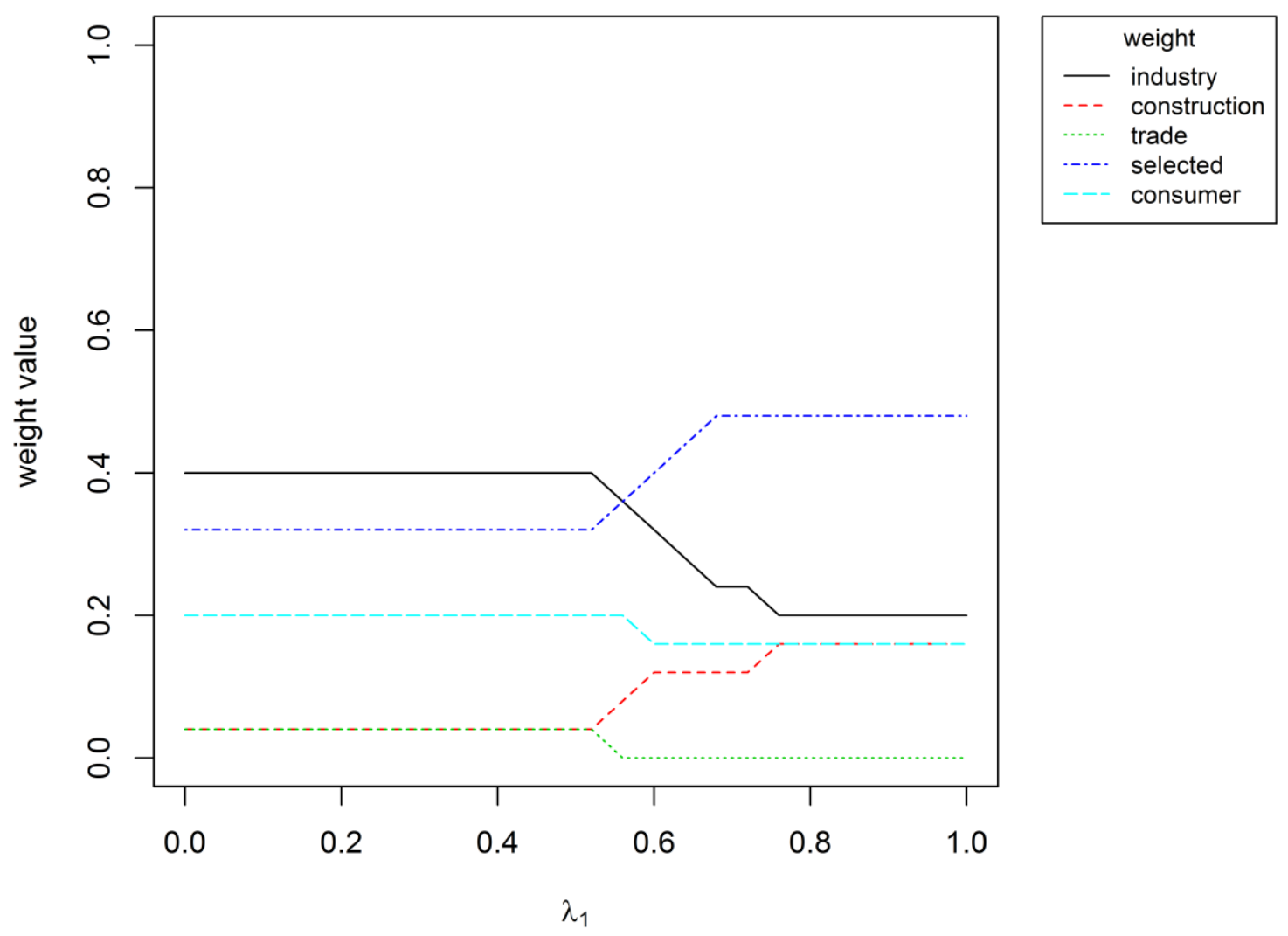

Source: own calculation

Figure 5 shows results for used metric of correlation coefficient and changes in the weighing scheme take place here for $\lambda_{1}>0.8$. This solution seems to be the most extreme variant because increasing the values of lambda 1 disproportionately increases the significance of the confidence indicator in selected services. In contrast, the others are set almost to zero and finally for $\lambda_{1}=1$ to zero. 
Figure 5: Weighting scheme for the Economic Sentiment Indicator (correlation coefficient)

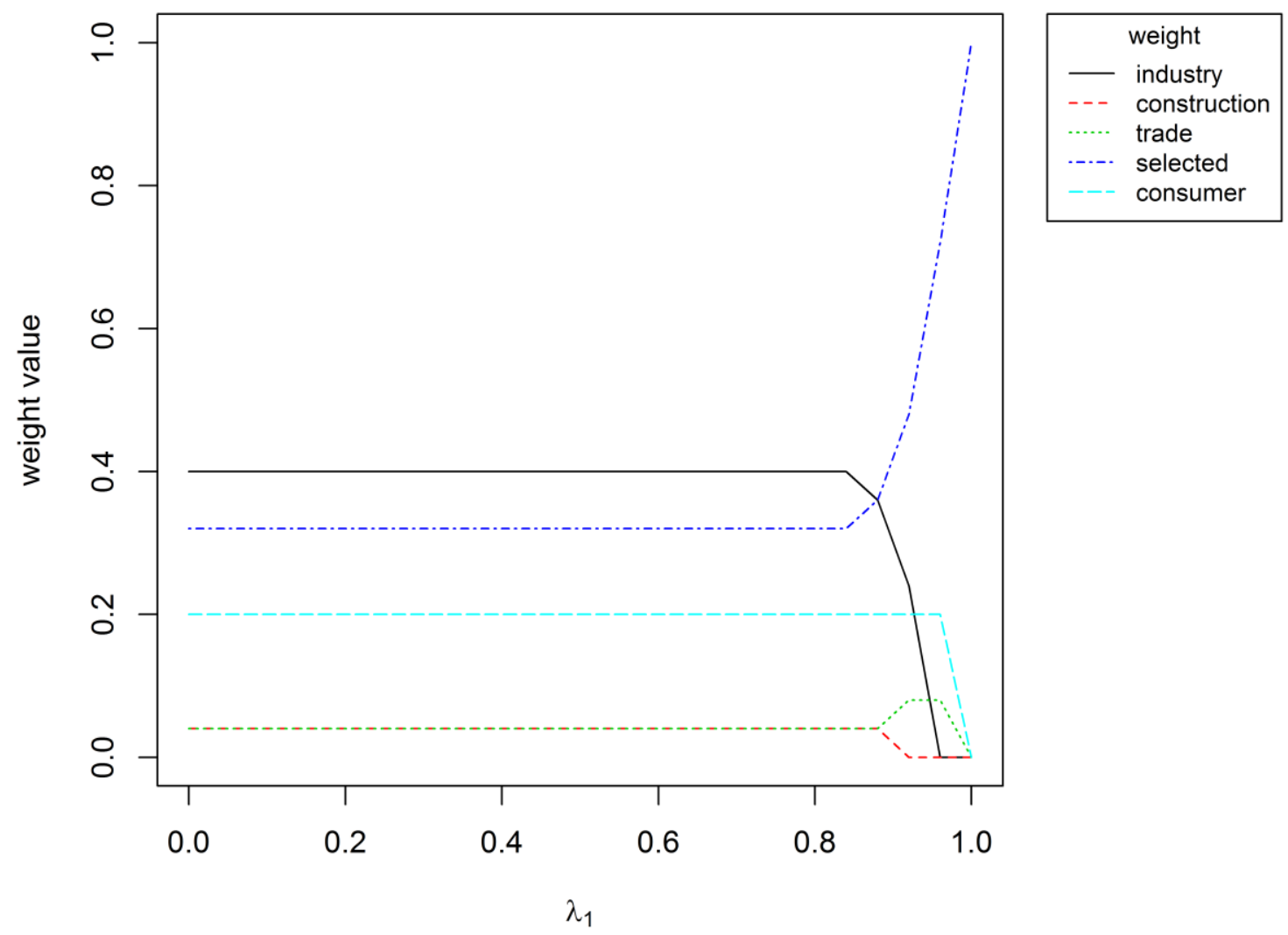

Source: own calculation

\section{Discussion}

In the current situation, we need indicators that can help with economic predictions. Business and Consumer Surveys are one of the most favourite tools. Mentioned surveys warn before the economic changes in the business cycle (Hölzl et al. 2019). Economic Sentiment Indicator which is the main result of the Business and Consumer Surveys - help with the predictions in the Czech Republic (Lehmann 2020). Unfortunately, there are still imperfections in the calculation - for example, the weighting scheme. It is the main reason why we focus on the improving this problem.

In our paper, we found the revised weighting scheme of Economic Sentiment Indicator using optimization with a penalty function. Except for the penalty function, we use three performance metrics, mean square error, mean absolute error, and Pearson's correlation coefficient, respectively, for finding the accuracy of the prediction ability of the gross domestic product by Economic Sentiment Indicator. Independent on the metric, the confidence indicator has the different weight. According to mean square error, the confidence indicator in industry has the most significant fall by way of the contract, the confidence indicator in construction weight increases. The confidence in trade and selected services, respectively, increases, too. The mean absolute error is the second metric. It is similar to the first one, because the confidence indicator in industry has a lower weight, too. The difference is connecting with the confidence indicator in selected services. MSE and MAE results are the possible results from the economic view. According to the first metric, we decrease the weight of the industry sector and increase the weights of the construction and trade sector. Using the MAE metric, we have similar results as the European Commission scheme (2020). The correlation coefficient does not seem that it is the right metric for our paper. Finally, we can say that the confidence indicator for industry should be lower and discuss increasing weights for the confidence indicator in construction and 
selected services. From the economic view, the growing importance of the services makes sense.

One of the limitations of this paper was the application only for one country. We choose the Czech Republic because we have access to the data and understand the development of the confidence indicators and relationship in the Czech economy. Thanks to aforementioned information; we can decide which metric is suitable and which is not and we can comment it. The reviewed weighting scheme maybe is not ideal for another country - but it is the same situation as with the current weighting scheme, which is set by the European Commission. We would suggest that each country use international weighting scheme (for international comparisons taken patronage by the European Commission) and a national weighting system that better suits their national business cycle development. It could be beneficial for the national and international economic prediction of the Gross Domestic Product, or Gross Value Added, respectively.

\section{Conclusion}

The weighting scheme of the Economic Sentiment Indicator is not a typical theme for the research paper. But we think that the reviewed national weighting scheme is beneficial for the getting better the prediction ability of the Business and Consumer Surveys which help us with the economic forecasts.

For the current situation, the best weighting scheme, which was calculated for the Czech Republic with the help of mean absolute error: industry $=40 \%$, construction $=4 \%$, trade $=4 \%$, selected services $=32 \%$, consumers $=20 \%$. Compared to the original scheme from the European Commission, the changes seem as a significant. We only change weights in the sectors: construction, trade and selected services. Despite these minor changes, there may be a significant increase in the predictive ability of Business and Consumer Surveys.

In the next research, we extend the paper by polynomic penalty function, and we will try to use the present methodology for finding the weighting scheme for the business cycle or gross valueadded predictions. After that, the finding weighting scheme will be visualized and compared with the short-term statistics for the better understanding the prediction ability of the Business and Consumer Survey (in the cooperation with the original weighting scheme). New weighting scheme will be applicable for the prediction of the Gross Domestic Product in the Czech Republic.

\section{Acknowledgement}

This paper has been prepared under the support of a project of the University of Economics, Prague - Internal Grant Agency, project No. F4/11/2020 " Improving the methodology of the Business Tendency Survey in the Czech Republic""

\section{References}

[1] ANCUSA, V., R. BOGDAN and O. CAUS, 2015, June. A Complex Network-Based Visual Analysis of Business Tendency and Consumer Opinion Surveys. In ECRM2015Proceedings of the 14th European Conference on Research Methods 2015: ECRM 2015 (p. 10). Academic Conferences Limited.

[2] BRAND D. A., M. SAISANA, L. A. RYNN, F. PENNONI and A. B. LOWENFELS, 2007. Comparative Analysis of Alcohol Control Policies in 30 Countries, PLoS Medicine, 0759 April 2007, Vol. 4, 4, e151:0752-0759, www.plosmedicine.org 
[3] CZECH STATISTICAL OFFICE, 2020. Business cycle surveys. Available at: https://www.czso.cz/csu/czso/business_cycle_surveys

[4] DIBIASI, A., K. ABBERGER, M. SIEGENTHALER and J. E. STURM, 2018. The effects of policy uncertainty on investment: Evidence from the unexpected acceptance of a farreaching referendum in Switzerland. European Economic Review, 104, pp. 38-67.

[5] EMERSON, R. A. and D. F. HENDRY, 1996. An evaluation of forecasting using leading indicators. Journal of Forecasting, 15(4), pp. 271-291

[6] EUROPEAN COMMISSION, 2020. User guide. Available: https://ec.europa.eu/info/sites/info/files/bcs_user_guide_en_0.pdf

[7] EUROSTAT, 2020. Glossary: Leading indicator. Available: https://ec.europa.eu/eurostat/statistics-explained/index.php/Glossary:Leading_indicator

[8] GOGGIN, J., 2008. An analysis of the potential of the European Commission business and consumer surveys for macroeconomic forecasting. Quarterly Economic Commentary: Special Articles, 2008(4-Winter), pp. 46-67.

[9] HÖLZL, W., S. KANIOVSKI and Y. KANIOVSKI, 2019. Exploring the dynamics of business survey data using Markov models. Computational Management Science, 16(4), 621-649.

[10] KAUFMANN, D. and R. SCHEUFELE, 2017. Business tendency surveys and macroeconomic fluctuations. International Journal of Forecasting, 33(4), 878-893.

[11] LEHMANN, R., 2020. Forecasting exports across Europe: What are the superior survey indicators?. Empirical Economics, 1-25.

[12] KEARNEY, I., 1991. A Preliminary Analysis of the CII/ESRI Business Survey Data. ESRI, mimeo.

[13] MEL,IHOVS, A. and S. RUSAKOVA, 2005. Short-Term Forecasting of Economic Development in Latvia Using Business and Consumer Survey Data (No. 2005/04). Latvijas Banka.

[14] OECD, European Commission, 2008. Handbook on Constructing Composite Indicators. Methodology and user guide. Available: https://www.oecd.org/sdd/42495745.pdf

[15] PTÁČKOVÁ, V., L. ŠTĚPÁNEK and V. HANZAL. Business and Consumer Surveys: the Weighting Scheme. In Löster, T., Pavelka, T. (ed.). International Days of Statistics and Economics 2019. Slaný: Melandrium, Libuše Macáková, 2019, s. 1234 - 1243. ISBN 97880-87990-18-6. URL: https://msed.vse.cz/msed_2019/article/182-Ptackova-Veronikapaper.pdf

[16] R CORE TEAM, 2014. R: A language and environment for statistical computing. R Foundation for Statistical Computing, Vienna, Austria. URL http://www.R-project.org.

[17] SAISANA, M. and S. TARANTOLA, 2002. State-of-the-art report on current methodologies and practices for composite indicator development, EUR $20408 \mathrm{EN}$, European Commission-JRC: Italy.

[18] SAMMUT, C. and G. I. WEBB, 2011. Mean Squared Error. Encyclopedia of Machine Learning. Springer, Boston, MA. https://doi.org/10.1007/978-0-387-30164-8_528

[19] SHARMA, A. K., 2005. Text Book of Correlations and Regression. Discovery Publishing Pvt. Ltd. ISBN: 8171419356 